Review Article

\title{
Psychological Benefits of Nonpharmacological Methods Aimed for Improving Balance in Parkinson's Disease: A Systematic Review
}

\author{
Rastislav Šumec, ${ }^{1,2}$ Pavel Filip, ${ }^{2,3}$ Kateřina Sheardová, ${ }^{1,2}$ and Martin Bareš ${ }^{2,3,4}$ \\ ${ }^{1}$ International Clinical Research Center (ICRC), St. Anne’s University Hospital, Pekařská 53, 65691 Brno, Czech Republic \\ ${ }^{2}$ First Department of Neurology, Faculty of Medicine, Masaryk University, St. Anne’s University Hospital, Pekařská 53, \\ 65691 Brno, Czech Republic \\ ${ }^{3}$ Central European Institute of Technology (CEITEC), Behavioural and Social Neuroscience Research Group, Kamenice 753/5, \\ 62500 Brno, Czech Republic \\ ${ }^{4}$ Department of Neurology, Medical School, University of Minnesota, Minneapolis, MN 55455, USA
}

Correspondence should be addressed to Martin Bareš; martin.bares@fnusa.cz

Received 19 February 2015; Revised 7 June 2015; Accepted 10 June 2015

Academic Editor: Karsten Witt

Copyright (c) 2015 Rastislav Šumec et al. This is an open access article distributed under the Creative Commons Attribution License, which permits unrestricted use, distribution, and reproduction in any medium, provided the original work is properly cited.

\begin{abstract}
Parkinson's disease (PD) is a serious condition with a major negative impact on patient's physical and mental health. Postural instability is one of the cardinal difficulties reported by patients to deal with. Neuroanatomical, animal, and clinical studies on nonparkinsonian and parkinsonian subjects suggest an important correlation between the presence of balance dysfunction and multiple mood disorders, such as anxiety, depression, and apathy. Considering that balance dysfunction is a very common symptom in PD, we can presume that by its management we could positively influence patient's state of mind too. This review is an analysis of nonpharmacological methods shown to be effective and successful for improving balance in patients suffering from PD. Strategies such as general exercise, robotic assisted training, Tai Chi, Qi Gong, Yoga, dance (such as tango or ballet), box, virtual realitybased, or neurofeedback-based techniques and so forth can significantly improve the stability in these patients. Beside this physical outcome, many methods have also shown effect on quality of life, depression level, enjoyment, and motivation to continue in practicing the method independently. The purpose of this review is to provide information about practical and creative methods designed to improve balance in PD and highlight their positive impact on patient's psychology.
\end{abstract}

\section{Introduction}

Parkinson's disease (PD) is a progressive neurodegenerative disorder resulting in multiple motor and nonmotor symptoms [1]. The primary symptoms are caused by reduced activity of dopaminergic cells in substantia nigra [2]. Additionally, other motor, associative, orbitofrontal, and limbic circuits, which connect other brain's areas to basal ganglia, are affected as well $[3,4]$. The disease is considered idiopathic, if occurring after the age of 50; however, some case can be attributed to mutation of several specific genes [5].

Cardinal motors symptoms can be merged under the acronym TRAP, which goes for tremor, rigidity, akinesia (bradykinesia), and postural instability [1]. Tremor is the most apparent and well known motor symptom. In most cases it is a rest tremor (maximal when limb is at rest), unilateral, and most prominent on the distal part of the limb and it disappears with an action or during sleep. Rigidity is caused by an excessive and continuous muscle contraction [1]. Just like tremor, it is often asymmetrical and is a usual cause of arthralgia, which may even be an initial sign of this disease [6]. Akinesia (or bradykinesia) represents slowness and difficulties around the whole movement process, regarding planning, initiation, and execution of movement. This symptom is especially problematic in terms of daily tasks such as getting dressed, writing, or sewing. Patients with PD usually have less difficulties with movement when some kind of external cue is provided [1,7]. Postural instability 


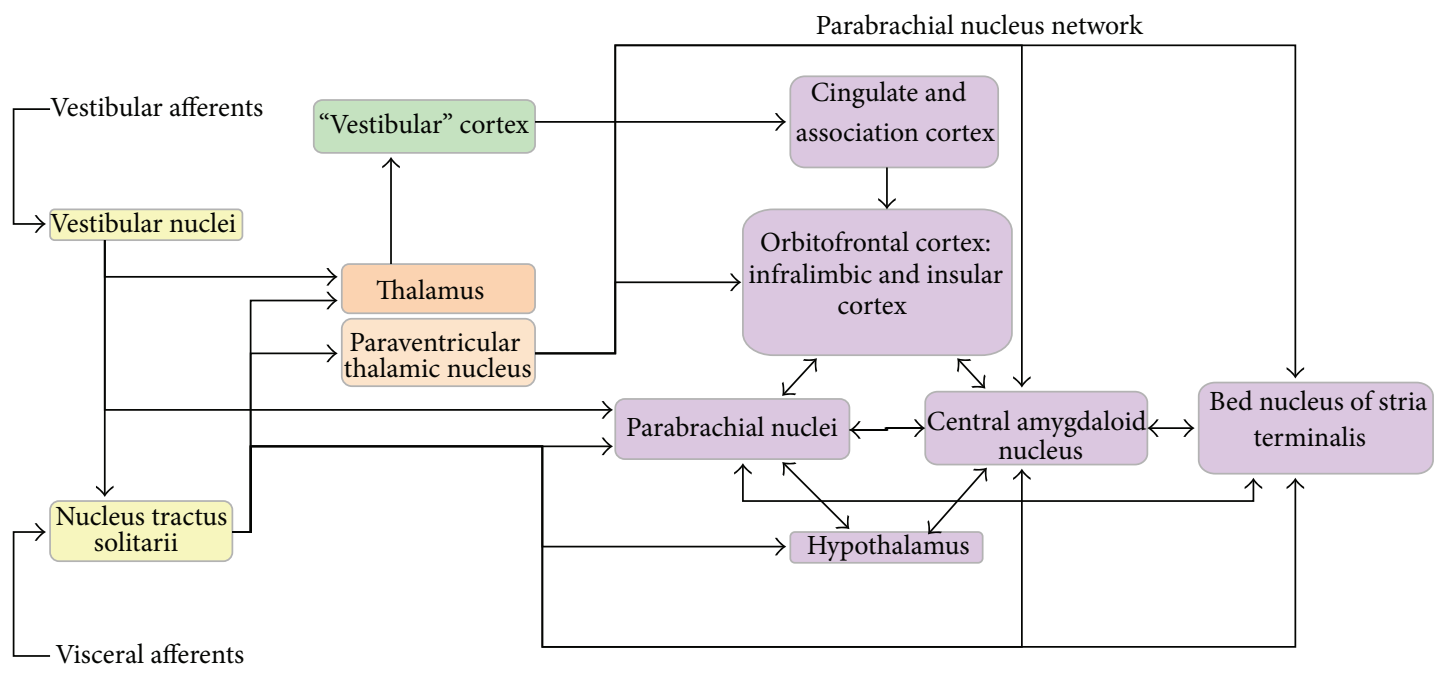

FIGURE 1: Neural balance-anxiety links.

and susceptibility to falls are other very serious and common symptoms occurring in $\mathrm{PD}$, which even worsen over time $[8,9]$. Balance dysfunction can be measured by multiple tests and scales (see Table 1).

Balance dysfunction has been identified as the main motor determinant of poor quality of life (QoL) [72-74]. In a particular falls, shuffling, and difficulty turning resulting from a postural instability are reported to be problematic [75]. Approximately $70 \%$ of patients report falls, often resulting in serious consequences such as fractures [76] or social stigma caused by embarrassment of falling in public [75]. Fear of falling can prevent patients from attending outdoor activities, which further reduces QoL. Performance in Timed Up and Go test (simple test requiring both static and dynamic balance) showed to be one of the important predictors of QoL [77]. Improvement of balance is considered to be one of the most relevant outcomes necessary for considering the treatment effective and successful [78]. Other important motor factors contributing to overall life quality are impairment of gait and adverse effects of patient's medication [79].

Nonmotor symptoms are represented by disorders of cognition, thoughts, mood, behaviour, and speech [1]. Cognitive impairments result especially in executive dysfunction, attention deficits, slow cognitive speed, recalling learned information, and visuospatial problems [80]. Most frequent mood difficulties are depression, anxiety, and apathy [1]. Depressive symptoms are present in $30-50 \%$ of PD patients. On one hand, they may be a psychological reaction to the disease; on the other hand, sometimes they occur even before the motor signs [81]. Depression provides the largest contribution to health related QoL, followed by postural instability, gastrointestinal symptoms, and urinary symptoms [82]. Anxiety has only recently attracted scientific attention, despite its high prevalence and a major impact on daily functioning and QoL. It is even reported as a significant factor resulting in deterioration of parkinsonian symptomatology $[83,84]$. Approximately $45 \%$ of PD patients experience symptoms of anxiety. Anxiety related diseases, such as social phobia, generalized anxiety disorder, and anxiety disorder not otherwise specified (NOS) are most often diagnosed in this population [84-86]. Apathy is a frequent psychiatric disturbance that can manifest even earlier than the motor symptoms of PD [87]. It is diagnosed in $20-36 \%$ of new-onset $\mathrm{PD}$ patients $[88,89]$. It has been shown to be related to more severe motor symptoms and higher risk of dementia development $[90,91]$. Psychotic symptoms, such as hallucination and delusions, occur in $4 \%$ of patients and are often associated with dopaminergic excess caused by the treatment [92].

1.1. Balance and Mood Disorders. Postural instability is strongly associated with all cardinal mood disorders, such as anxiety, depression, and apathy [93, 94]. Anxiety, being the most researched mood disorder in relation to balance showed to be correlated with it in multiple neuroanatomical, experimental, and clinical studies.

Anxiety and balance share some common neural circuits [95, 96] (see Figure 1). Central circuits that process afferent visceral and vestibular information related to balance control include vestibular nuclei, nucleus tractus solitarii, thalamus, and vestibular cortex. These pathways connect to parabrachial nucleus network, which is involved in generating emotional and physiological manifestations of anxiety and fear [97].

Vestibular nuclei and nucleus tractus solitarii send ascending neurons to prosencephalon. Nucleus tractus solitarii sends axons directly to amygdala, thalamus, basal forebrain (bed nucleus of the stria terminalis), hypothalamic nuclei $[98,99]$, and the paraventricular thalamic nucleus. Paraventricular thalamic nucleus sends neurons to multiple regions, involving central amygdaloid nucleus, bed nucleus of the stria terminalis, and infralimbic cortex [100]. Neural tracts connecting the vestibular nuclei to the parabrachial nucleus are especially important. They represent a direct link between the vestibular networks and circuits involved in manifestation of anxiety and emotions [97, 101, 102]. Parabrachial nucleus therefore represents a junction for ascending vestibular and 


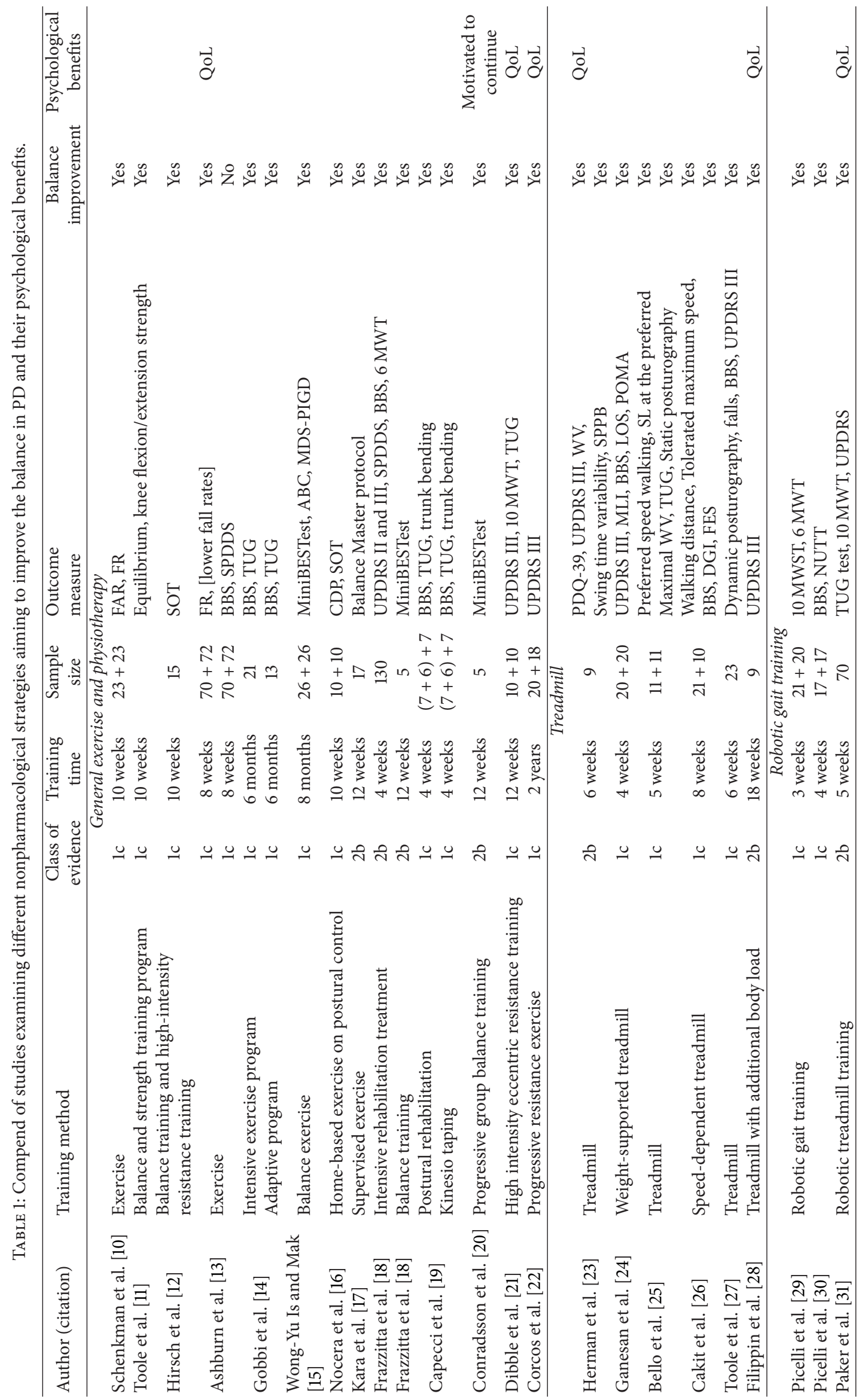




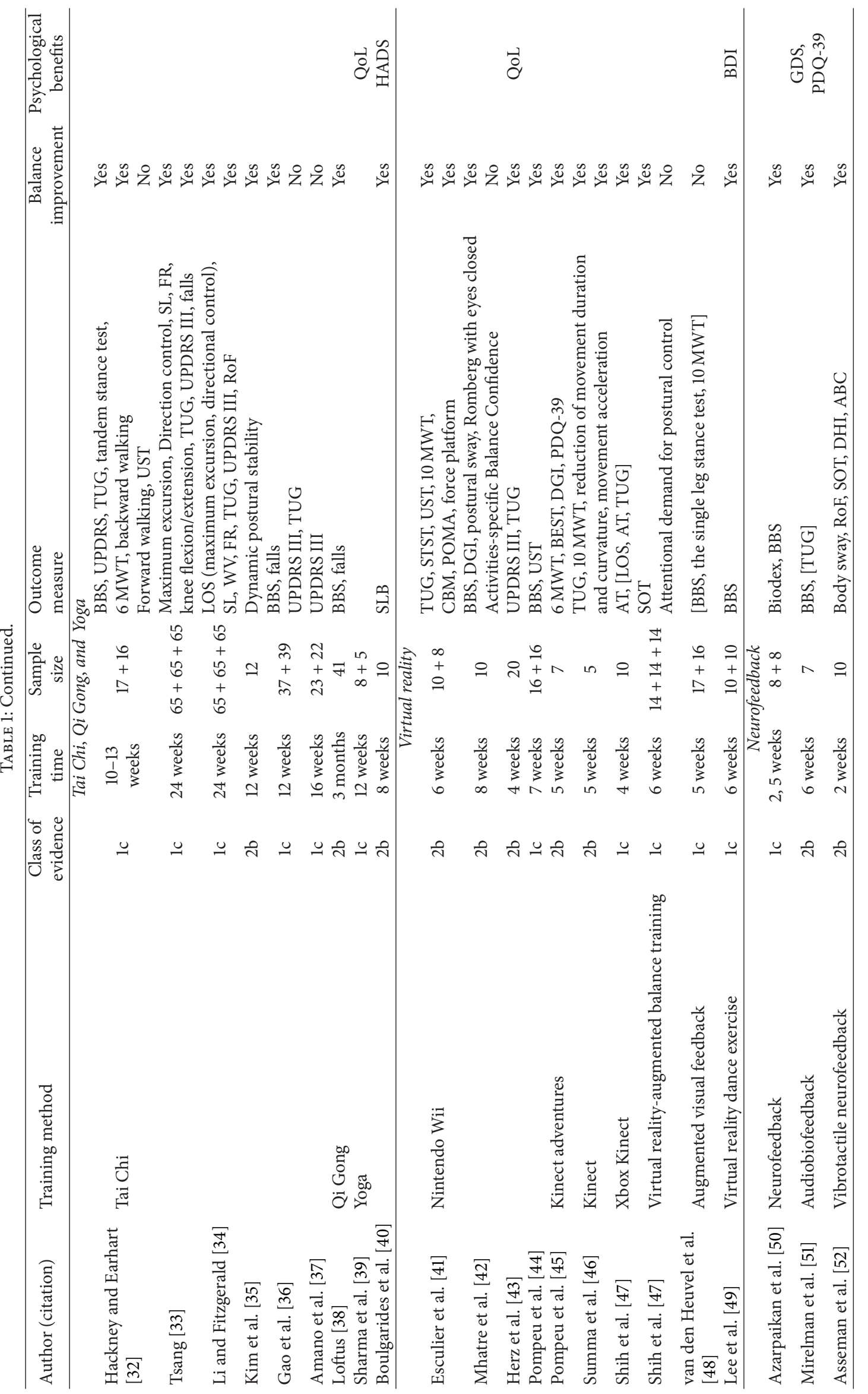




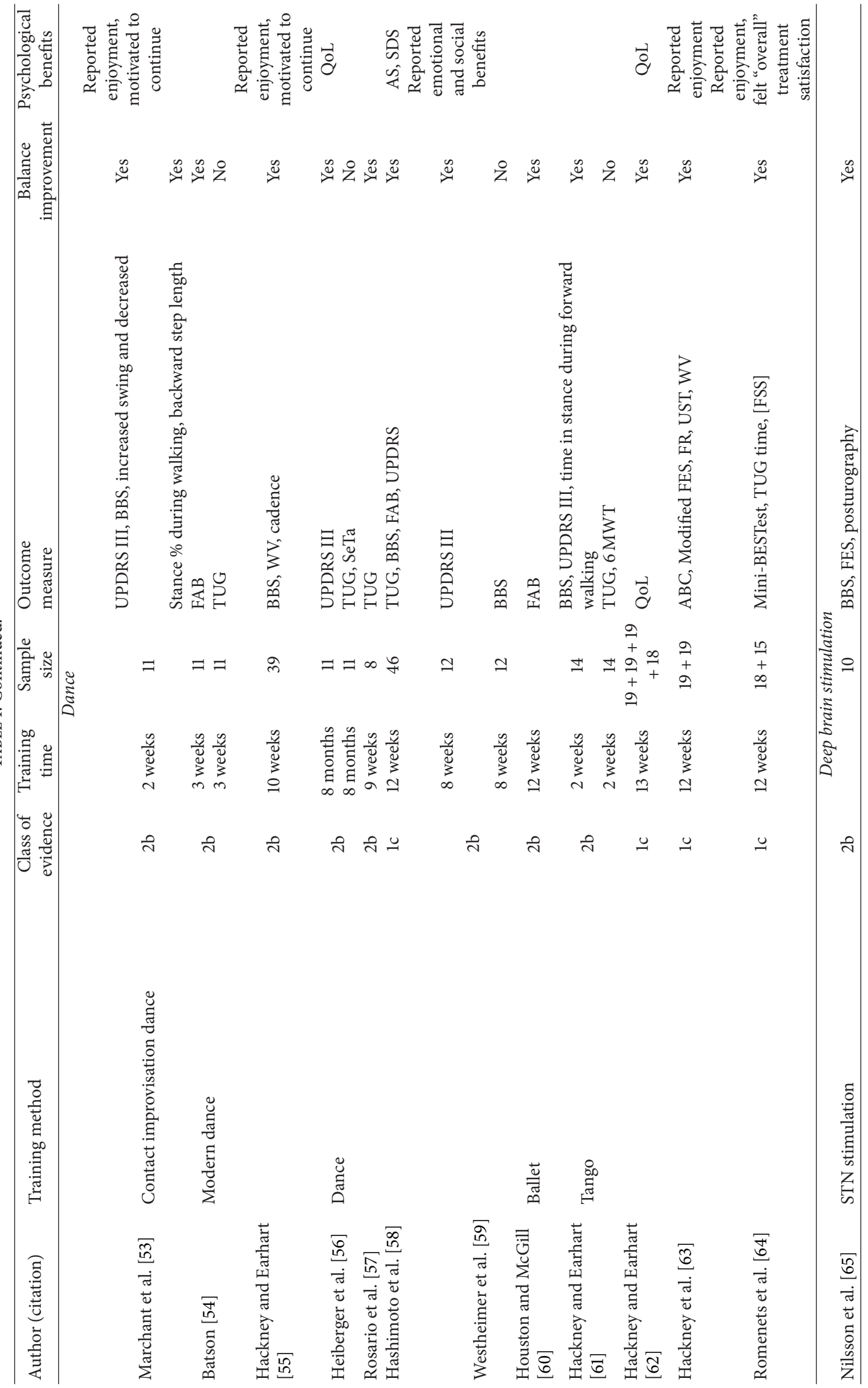




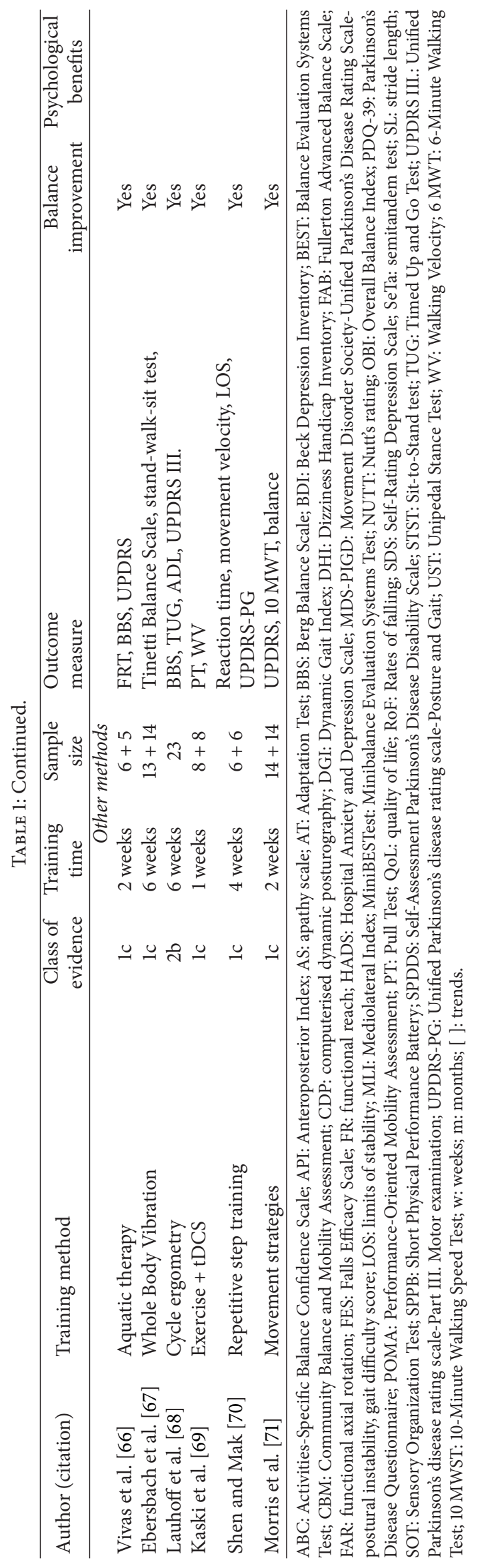


visceral information to basal forebrain, hypothalamic, amygdaloid, and these cortical regions construct an integral part of neural links that mediate anxiety and fear $[97,103]$.

An existing link between balance and anxiety has already been reported in studies using animal models. Mutant vestibular Headbanger ( $\mathrm{HdB}$ ) mice (with mutation resulting in imbalance) demonstrate progressive balance disability and elevated anxiety, when compared to wild type mice. After attending a balance training, $\mathrm{HdB}$ mice improved their balance and decreased the level of anxiety. Balance dysfunction therefore seems to have a causal effect on anxiety. Therefore improving it may be the right treatment for some anxiety disorders [104].

This causal hypothesis has also been tested on 20 healthy adults with the same results. After attending Balance and Reform program, their anxiety has significantly decreased and the level of self-esteem has significantly increased [105]. Study with children confirmed that children suffering from balance dysfunction had higher anxiety and lower self-esteem than healthy ones. Also in this case, the nonpharmacological balance training not only improved their balance, but also reduced anxiety and increased self-esteem when compared to the control group, which did not attend the exercise [106]. Detailed questionnaires and balance tests confirmed an excessive sensitivity of anxiety disordered children to balance-challenging situations [107].

Clinical studies with patients suffering from PD also suggest that there might be a clinical correlate to the connection of neural circuits responsible for balance and anxiety. A systematic review concerning factors associated with depression and anxiety among adults with PD mentioned that they seem to influence multiple motor or nonmotor symptoms [108]. It has been revealed that PD patients with balance impairment and gait difficulties were more likely to feel anxiety than patients whose dominant symptom was tremor [86]. Anxiety also seems to be associated with gait problems in PD [109] and is considered be a crucial mechanism underlying freezing of gait [110]. It has also been found in both PD patients and controls that the balance can be equally altered by anxiety, supporting the connection between neural links controlling emotion and stability [94].

Depression and apathy in terms of their connection to postural instability have been the major focus of limited number of studies. Although both symptoms are well characterized anatomically and are known to share deficits in cingulate and prefrontal cortex [111-113], their neuroanatomical basis for postural instability is less clear. However, it is known that depression, apathy, and balance all share basal ganglia circuitry and the dysfunction of dopamine system [111-114]. It has been shown that especially non-tremor-dominant PD patients have problems with these mood disorders [115]. It has also been observed that in early stages of $\mathrm{PD}$, gait impairment is often associated with mild depressive symptoms [116]. In a statistical analysis of demographic, clinical, depression, and apathy data of patients with $\mathrm{PD}$, apathy and depression have been associated with postural instability. It has been suggested that incidental postural instability should be of high concern in management of these mood disorders. Future research is necessary to better assess the pathophysiology and treatment of depression, apathy, and balance dysfunction [93].

1.2. Balance and Medication Treatment Limitations. Even though there is no cure for PD, medication, surgery, and palliative care can provide relief from some symptoms. However, pharmacological treatment hardly influences balance dysfunction. Treatment with levodopa even increases postural sway abnormalities [117].

It would therefore be very beneficial to find and apply more alternative, nonpharmacological solutions for treating balance dysfunction in patients with PD. There are multiple methods for improving balance of PD patients and the purpose of this review is to increase the awareness of this choice as a potential way to positively affect patient's mind and improve their QoL too.

\section{Materials and Methods}

In February 2015, we systematically searched PubMed, Web of Science, and EBSCO for articles pertaining nonpharmacological methods for improving balance in PD patients. We used the following keywords: Parkinson's disease, nonpharmacological, alternative, balance, instability, posture, and axial. The search of electronic databases identified 2160 articles. Titles and abstracts were reviewed to meet following inclusion criteria: (1) studies done on PD patients, (2) nonpharmacologically based, (3) aimed for improving balance, (4) published in last 20 years (1995-2015 (February)), and (5) full-text articles. After the reviewing process, 72 articles met the inclusion criteria. In the next step, full papers were analyzed with concern to study design and methodology. Following data were analyzed from the included studies: study characteristics (names of authors), training method, class of evidence, study design, duration of trial period, sample size, types of outcomes assessed, and the effect of the intervention. Any disagreement was resolved through discussion. After the reviewing process, 8 articles have been excluded because of their small sample size. 64 remaining studies have been further analyzed and commented on in this review (for compend, see Table 1).

2.1. General Exercise and Physiotherapy. The most researched practically applied strategy to improve the stability in PD is general exercise and physiotherapy. Exercise is structured and planned physical activity improves specific aspects of physical fitness [118]. Models of rehabilitation use multiple compensatory strategies as therapeutic approach. Evidence shows that exercise can also benefit in terms of neuroplasticity and brain's ability to reconstruct [119]. Randomised control trial (RCT) on exercising patients with PD showed positive changes in functional axial rotation (FAR) and functional reach (FR) in comparison with the control group [10]. The exercise showed the ability to improve equilibrium and modest gains in knee flexion and extension strength [11]. In RCT, it has been showed that it also results in consistent trend towards lower fall rates, lower rates of injurious falls needing medical attention, and higher score in QoL questionnaire [13]. Physiotherapy has shown to be effective in improving 
balance regardless of PD subtype (tremor dominant or akinetic-rigid) [18].

Exercise has shown to improve balance regardless of focusing on aerobic component. The thing that seems to matter the most is the focus on motor coordination, balance training, flexibility, and strength [14]. A RCT examining specifically designed exercise balance programme targeting multiple balance domains showed to be much more efficient in improving balance, stability, and gain in comparison to simple upper limb exercise [15]. The addition of method called Kinesio taping (KT) has not shown to have any further effect on balance [19].

An important question is whether the exercise is also effective when applied at home, without any special equipment, making it more practical and accessible for PD patients to attend. Home exercise intervention has also been proven to be effective in terms of improvement of postural control and balance [16]. A study using before-after study design testing supervised exercises on measures of static and dynamic balance have also proved to be effective, especially in terms of maximum excursion of limits of stability (LOS) [17].

When comparing a single balance training with training combining balance and resistance in a RCT study, both approaches show positive impact on balance; however, the effect is larger in the combined training [12]. Resistance exercise showed not only to improve balance, but bradykinesia and QoL too [21]. Balance training seems to be motivational for its attendants since most of them report that they would recommend it to other people [20].

2.2. Treadmill. Treadmill has also shown a potential to improve balance and gait in PD. The possible basis for this improvement is related to proprioceptive sensory cues provided by belt movement of this device [120]. When applied to people with $\mathrm{PD}$, a pilot study using before-after design for treadmill training resulted in improvement in multiple balance scales as well as in QoL questionnaire [23]. When comparing the efficiency of assisted weight bearing treadmill training and the treadmill training alone, results show an improvement in dynamic posturography, number of falls, balance scales, and gait tests equally without any superiority of one method over the other [27]. When comparing walking on a treadmill and walking overground, both methods resulted in the increase of preferred speed walking; however, only the treadmill group improved in the stride length at the preferred and maximal walking speed, as well as other static posturography tests [25]. In RCT, partial weight-supported treadmill gait training (PWSTT) showed to be much more effective in terms of balance and gait improvement than conventional gait training, suggesting it to be a better interventional choice than gait physiotherapy [24]. Incremental speed-dependent treadmill training also showed trends towards improvement of postural instability, dynamic balance, and fear of falling [26]. Using additional body load resulted in improvement of multiple motor and nonmotor factors related to QoL [28].

2.3. Robot Assisted Gait Training. Electromechanical devices used to assist individual's gait and stepping have also been suggested as a potential intervention. When comparing effects of robot-assisted gait training (RAGT) and conventional physiotherapy on walking, RAGT showed to improve walking more efficiently [29].

RAGT has been examined in a RCT on postural stability too, also showing a significant improvement of balance when compared to conventional physiotherapy group [30]. Robotic treadmill training proved to be useful not just in improving motor symptoms, functional mobility, and walking capacity, but also a transient improvement in QoL [31]. Robot-assisted training has therefore proved to have a potential to enhance the effect of conventional physiotherapy not only in terms of gait, but also of balance.

2.4. Tai Chi, Qi Gong, and Yoga. Considerable amount of studies examined the potential of multiple exercises inspired by famous eastern techniques, such as Tai Chi (TC), Qi Gong, and Yoga. In particular TC has recently gained a lot of attention as an attractive intervention. The practice of this martial art involves slow and controlled movements and a need to maintain different kinds of postures. Therefore it has been suggested as an effective way to manage balance dysfunction. In a pilot study on PD patients TC intervention showed improvement in multiple balance and gait scales and tests [32]. In a RCT study, TC training also improved multiple motor control abilities, such as direction control, maximum excursion, functional reach, knee extension, and flexion peak torque, when compared to the control (stretching) group [33, 34]. TC training also leads to better dynamic postural control during obstacle negotiation, meaning that PD patients could more effectively negotiate an obstacle from the position of quiet stance at a normal speed, which results from a better balance control [35]. TC has also shown the potential to significantly improve balance, but also a significantly decrease in experience of falls, when compared to the control group. However, some measurements such as UPDRS III scores and TUG did not differ in comparison to the control group [36]. These optimistic results are not shared by all the studies. One RCT study showed that 16 weeks of TC training were ineffective in either gait performance, nor gait initiation, or the reduction of parkinsonian disability [37].

Qi Gong is another interesting balance training tested on individuals with PD. This Chinese martial art involves systematic training exercise, coordinated rhythmic movements, different breath patterns, and meditation. This mindful exercise is also reported to be involved in neuroplasticity, brain reorganization, and its repair. When tested on PD individuals, this method showed to have a positive influence on postural stability and Parkinson-related falls [38].

Another interesting and only recently researched method for postural stability is Yoga. This exercise was chosen as an intervention because of its known potential to increase flexibility, balance, and muscle strength [121-123]. Following two successful case studies $[124,125]$, one RCT study on PD patients reported that, alongside effects on physical aspects, yoga has also shown to improve depression, anxiety and QoL $[39,40]$.

2.5. Virtual Reality. Virtual reality (VR) and visual feedback training are becoming more frequent subject of research as 
an intervention for improving balance deficits for different types of population $[126,127]$. One of these methods is The Nintendo Wii (Wii). Wii Fit balance board analyses data from the user's movements and uses them to perform a specific action in the game. The game then sends visual feedback to the user using a sensory-enriched environment. In an experimental noncontrolled study on patients with $\mathrm{PD}$, Wii showed improvements in many balance tests. Authors suggested Wii to be an effective balance programme for PD patients, which is also practical because it can easily be used at home [41]. Wii seems to be effective not only on balance, but on the gait and postural sway too. However, in one prospective cohort study, it did not show to improve the balance confidence [42]. Wii intervention showed to have positive short-term motor and nonmotor effects along with an increase of QoL in PD patients. Authors encourage further studies to determine also long-term benefits of Wii [43]. Another study showed positive effects of virtual reality dance exercise on balance, depression, and activities of daily living. In this study, the experimental group, using Nintendo Wii, tried to mimic character on TV monitor, dancing to their favorite songs. If they mimicked properly, they felt vibrations of the remote control and were praised by the game [49]. When comparing the effect of Wii-based training versus balance exercise therapy, both groups of patients showed an improvement in activities of daily living, with no additional advantages in either of techniques [44].

Based on these findings other researchers hypothesized that Kinect Adventures games would be feasible and safe for people with PD too. When tested in a single-group blinded trial, the games showed an improvement in multiple scales of balance and gait, concluding it to be another effective strategy for enhancing patient's stability [45]. Similar study supported this claim by reporting an improvement in both balance and gait in 3 out of 5 observed subjects. The method has been therefore reported as a feasible, affordable, and safe option for the rehabilitation. However, their results will have to be confirmed by a larger-scale study [46].

One interesting trial compared effects of VR-based balance training using Xbox Kinect and conventional physiotherapy on functional balance and postural control. VR group showed a significant improvement in certain balance measures and positive trends in multiple subscales of Limits of Stability and gait. One RCT study has showed that Xbox Kinect seems to have some therapeutic potential; however so far there is no strong evidence to confirm its advantages above the conventional approach [47].

When comparing VR-augmented balance training, conventional balance training, and untrained group, VR training shows an additional improvement in certain equilibrium scores [128]. However, similar study reported no superiority of augmented visual feedback training over the conventional technique. However, it still proved to be another feasible and safe strategy to improve balance [48].

2.6. Neurofeedback Training. Another inspiring technique is Neurofeedback Training (NFT). In this method a participant receives feedback of signals which represent his/her subconscious neural activities. By observing his/her brainwaves on a computer screen, it is possible to learn to control and change them. This training leads to a point when one is able to control their brainwaves subconsciously not only through the exercise, but in their everyday life too [129]. It is already being used for treating many brain disorders [130]. In PD, balance and gait are tasks requiring attention. Therefore by improving patient's attention it is possible to maintain the balance for longer period of time $[131,132]$. It is known that there is a relationship between particular levels of performance and concrete patterns of cortical activity. By using NFT for recreating these patterns in patients with motor deficiencies, it might be possible to enhance their performance. When applied on PD patients in a RCT study, NFT showed an improvement in both static and dynamic balance [50].

Researchers have tried to prove the same point using audiobiofeedback. In this method patients received an auditory feedback modulated by their movement. It showed an improvement in balance. The training also appeared to have a positive impact on psychosocial aspects of $\mathrm{PD}$ and the depression level of patients. Patients reported a high satisfaction attending this training [51].

Other researchers claimed that audiobiofeedback has disadvantages regarding the fact that audio information is quite nonintuitive and therefore it is not possible for patients to react on it fast enough. They suggested more intuitive, vibrotactile neurofeedback stimulus, which has been reported to have much faster reaction time [52]. Vibrotactile NFT really showed an ability to improve balance and also a potential to reduce the number of falls [133].

2.7. Dance. Dance is a multidimensional activity offering auditory, visual, and sensory stimulation, musical experience, social interaction, memory, motor learning, and emotional perception, expression, and interaction [134]. Several uncontrolled studies report that people with PD are motivated to attend dance lessons regularly, to have a great compliance and even a tendency to continue their attendance after the study is finished $[55,62]$.

Tango, as one of the most researched dances in terms of balance in PD, is reported to be very helpful for improving QoL. It puts the training of balance and gait in environment necessary for social interaction and close work with a dancing partner [62]. A noncontrolled trial of short and intensive tango lessons showed to significantly improve balance, however, not the gait [61]. When comparing effects of tango and conventional exercise on healthy elders and elders with PD in a RCT study, only the PD tango group improved all measures of balance, falls, and gait. Moreover, the PD tango group was more confident about balance than the PD exercise group. Both groups have reported a lot of enjoyment of their tango experience and overall treatment satisfaction $[63,64]$.

However, some researchers ponder on possible disadvantages of tango, regarding its requirement to memorize exact movements and the fact that some patients might just not be comfortable performing a certain style and aesthetics which tango requires. They suggested more of an improvising dance, which may offer more accessible technique, while still keeping the functional and social benefits of tango. Socalled Contact Improvisation (CI) dance directs the dancer's 
attention to nonverbal communication and sensation rather than to visible appearance or specific movement sequences. CI challenges to adapt to unpredictable movement coming from tactile interaction with the dancing partner. In one noncontrolled study, CI shows significant improvements in multiple balance scales and tests. Additionally, PD dancers have expressed a lot of enjoyment and a motivation to attend future CI classes [53].

An intensive trial of modern dance for 11 adults with early-to-middle stage PD also showed an improvement in Fullerton Advanced Balance Scale, however, not in Timed Up and Go test [54]. When comparing effects of partnered and nonpartnered dance on balance and mobility, both groups showed improvement in balance and walking. However, only partnered participants expressed more enjoyment from classes and an interest to continue with it in future [135]. Dance shows to have short-term benefits on motor functions of PD patients; however, in one uncontrolled study, no improvement is reported regarding Timed Up and Go test and semitandem test. Even though it shows to improve QoL not only in patients, but their caregivers [56], dance therapy positively affects patient's mood, lowers their apathy and depression levels, and improves their neuropsychological performance $[57,58]$. Apart of physical benefits, PD patients attending dance classes report emotional and social benefit too [59].

An interesting dance for managing a balance dysfunction is ballet. In ballet one needs to concentrate on body alignment, posture, and the coordination of the whole body. It challenges dancer's strength, stability, and encourages to train different movement qualities and dynamics. In case of PD patients, it showed to improve stability and balance, however, not the posture. Also in this case, participants were very motivated and reported the ballet-lessons to be an important aspect of their lives [60].

\subsection{Deep Brain Stimulation. Deep brain stimulation (DBS)} is another nonpharmacological option that has been tested on balance dysfunction in PD patients. This invasive method is widely used for those patients with motor symptoms which cannot be further managed by medication therapy. Candidates for this procedure are very carefully chosen by multidisciplinary team (neurologist, neurosurgeon, neuroradiologist, and neuropsychologist). Because of higher risk of cognitive decline and affective disorders after implantation of DBS in patients who have already had cognitive or affective problems before the operation, candidates for DBS should be carefully psychologically tested for signs of dementia or major depression [136].

However, efficiency of DBS on balance is not entirely clear. While some studies report improvements in posturography measures and balance scales $[65,137]$, other report that DBS may even worsen patient's gait, stability, and risk of fall [138]. Inaccurate positioning of the stimulating electrode can result in stimulation-induced freezing [139]. If the current spreads to the substantia nigra or other adjacent regions, it can cause akinesia and negatively affect patient's walking abilities. A meta-analysis showed that, during the first year after the surgery, the effect of subthalamic nucleus DBS on postural stability roughly equals the preoperative effect of medication [140]. Another problem is the worsening of axial motor functions despite the DBS treatment in the long term [141-144]. It has been reported that 35\% patients develop worsening of postural stability after 5 to 8 years after the procedure [142]. Stimulation of pedunculopontine nucleus (PPN) has been proposed as an alternative for PD patients with axial signs. It has been shown to be more effective on axial signs than stimulation of subthalamic nucleus. However, these findings still need to be replicated in a larger number of patients and there have not been yet done a study with a high class of evidence that analyzed this issue [145].

2.9. Other Techniques. Another interesting method is the aquatic therapy. When compared to the conventional balance training in a RCT, it showed to have a bigger effect on postural stability in PD patients [66]. When comparing a whole body vibration (WBV) and conventional physiotherapy on disturbances of balance and gait there was no evidence for the superiority of WBV [67]. In one quasiexperimental study, cycle ergometry also showed to have a significant positive effect not balance impairment and PD-related disability [68]. Comparing the effect of transcranial direct current stimulation (tDCS), physical training and the combination of the two on balance and gait in $\mathrm{PD}$ also brought interesting results. It was shown that even if there is no benefit of using tDCS alone, when combined with physical training it increases gait speed and improves balance even more significantly than when using physical training alone [69]. As one RCT study has shown, another successful way to improve balance is repetitive step training, a volitional and compensatory step program focused on stability and gait. It showed improvement in multiple tests examining the patient's balance, stability, and gait [70]. Movement strategy training (MST), as another proposed technique, teaches people with $\mathrm{PD}$ to use their frontal cortex to move faster, more easily, and safely by using their cognition. By using focused attention, external cues, visualization, and mental rehearsal, participants are trained in their general mobility. When compared with the usual exercise in a RCT, participants of MST group showed improvements on several outcome measures, including balance and gait tests. However, participants did not manage to maintain all these long-term improvements [71].

\section{Discussion}

Basically all methods analyzed in this review showed positive results in terms of balance. Out of 72 studies, 70 have shown positive results concerning balance and 24 reported positive influence on patient's well-being. Studies varied in terms of study design, training time, sample size, and the outcome measures. Generally, studies examining physiotherapy have had the highest class of evidence, 13 of them being RCT with large sample size. Three of physiotherapy-based studies reported a better QoL $[13,21,22]$ and 1 of them declared participants motivation to continue [20]. Four out of 6 treadmill-based studies have been RCT with sample size varying from 22-40 participants, all of them being successful in improving postural stability. Psychological benefits have been 
reported in 2 of them $[23,28]$, both of them lacking control group. Robotic gait training was assessed by 3 studies, 2 of them being RCT with sample sizes between 34 and 41 participants. Improved QoL was observed in the third one without control group, studied on $70 \mathrm{PD}$ patients [31]. Tai Chi was examined by 5 RCT applied on large sample sizes varying from 45 to 195 subjects and one noncontrolled applied on 12 patients only. However, the question on psychological effect of this method in PD is not answered yet. Yoga, on the other hand, showed a lot of positive effects on participant's mind, such as enjoyment, relaxation, lowering the anxiety, and depression level $[39,40]$. Since there was only one RCT with sample size of 13 participants only, these results should be further confirmed on larger studies [39]. As for virtual reality-based techniques, studies varied in study design (5 RCT, 5 noncontrolled trials), examining samples of medium size (between 18 and 42 subjects) with consistent training time (between 4 and 7 weeks) and 2 studies reporting positive psychological impact on patient's depression and QoL [43, 49]. Neurofeedback proved to be effective and useful in 3 out of 3 studies, one of them being RCT with 16 patients [50], other two not controlled studies with sample size no bigger than 10 patients [51, 52]. Dance, especially tango, seems to have perhaps the most promising results in terms of both balance and psychological well-being. Out of 13 reviewed studies, 9 have reported participants satisfaction, emotional and social benefits and improvement in apathy and depression scales. 4 of 13 studies were RCT with large size groups (up to 75 participants), 8 were noncontrolled with medium size groups (between 8 and 39 participants) and one was a case study. Three studies examined the effect of DBS on balance, however, RCT assessing this issue has not been done yet, nor have they measured any psychological aspects related to better stability $[137,145,146]$. Other RCT testing techniques such as aquatic therapy [66], Whole Body Vibration [67], tDCS [69], and movement strategies [71], with group size varying between 11 and 28 participants, all showed promising results.

Some studies have been excluded from our analysis because of low level of evidence. Interesting ideas such as footwear modifications [147], box [148], and multidimensional exercise [149] are very compelling methods showing positive results in terms of both balance and patient's wellbeing. However, because of their small sample size, larger studies are necessary to prove their effectivity.

Even though there are many effective and creative methods that improve balance of patients with PD, they are not used that often due to some of their limitations. Because of an apathetic nature of $\mathrm{PD}$, patients have low expectations that often limit their motivation to attend the method and keep their practice. Another important fact is that, in comparison to the pharmacological treatment, nonpharmacological methods are more time-consuming, making it difficult to include in everyday life. Some patients cannot comply simply because their fear of falling is too strong [150]. Another problem might be financial, such as high health care, medication, and travel cost, which sometimes make these therapies inaccessible and difficult for patients to maintain their participation [16].

\section{Conclusions}

The current review synthesized compelling evidence of efficiency of multiple methods proven to increase balance and stability in PD and highlights their potential for psychological benefit. Balance problems and psychological problems such as anxiety, depression, and apathy are very common in PD patients and all result in impaired QoL. Neuroanatomical [95], experimental, and clinical studies on animal models [104], children [106, 107], healthy young adults [105], and PD patients $[86,94,108-110]$ support the hypothesis that balance and mental well-being are interconnected and should not be overlooked. Taking into consideration that pharmacological therapy has its limitations and comes with many side effects, employing scientifically proven strategies influencing balance and improving quality of life appears to be a reasonable choice to make.

\section{Compend of Anxiety Scales}

BAI: Beck Anxiety Inventory

HADS: Hospital Anxiety and Depression Scale

SAS: Self-Rating Anxiety Scale

ASI: Anxiety Status Inventory

STAI: State Trait Anxiety Inventory

HARS: Hamilton Anxiety Rating Scale

MINI: Mini-International Neuropsychiatric Inventory (section for anxiety)

NPI: Neuropsychiatric Inventory (section E).

\section{Conflict of Interests}

The authors declare that there is no conflict of interests regarding the publication of this paper.

\section{Acknowledgments}

This work was supported by the project "Central European Institute of Technology (CEITEC)" (CZ.1.05/1.1.00/02.0068) from the European Regional Development Fund and by Ministry of Health of the Czech Republic, research Grant NT13437 and project "International Clinical Research Center (ICRC)."

\section{References}

[1] J. Jankovic, "Parkinson's disease: clinical features and diagnosis," Journal of Neurology, Neurosurgery and Psychiatry, vol. 79, no. 4, pp. 368-376, 2008.

[2] S. M. Hague, S. Klaffke, and O. Bandmann, "Neurodegenerative disorders: Parkinson's disease and Huntington's disease," Journal of Neurology, Neurosurgery and Psychiatry, vol. 76, no. 8, pp. 1058-1063, 2005.

[3] A. M. Bonnet, M. F. Jutras, V. Czernecki, J. C. Corvol, and M. Vidailhet, "Nonmotor symptoms in Parkinson's disease in 2012: relevant clinical aspects," Parkinson's Disease, vol. 2012, Article ID 198316, 15 pages, 2012.

[4] J. A. Obeso, M. C. Rodríguez-Oroz, B. Benitez-Temino et al., "Functional organization of the basal ganglia: therapeutic implications for Parkinson's disease," Movement Disorders, vol. 23, supplement 3, pp. S548-S559, 2008. 
[5] S. Lesage and A. Brice, "Parkinson's disease: from monogenic forms to genetic susceptibility factors," Human Molecular Genetics, vol. 18, no. 1, pp. R48-R59, 2009.

[6] F. S. Fung and P. D. Thompson, Parkinson's Disease and Movement Disorders: Rigidity and Spasticity, Tolosa, Hagerstown, Md, USA, 2007.

[7] M. C. Rodriguez-Oroz, M. Jahanshahi, P. Krack et al., "Initial clinical manifestations of Parkinson's disease: features and pathophysiological mechanisms," The Lancet Neurology, vol. 8, no. 12, pp. 1128-1139, 2009.

[8] M. A. Hely, J. G. L. Morris, R. Traficante, W. G. J. Reid, D. J. O'Sullivan, and P. M. Williamson, "The Sydney multicentre study of Parkinson's disease: progression and mortality at 10 years," Journal of Neurology, Neurosurgery and Psychiatry, vol. 67, no. 3, pp. 300-307, 1999.

[9] B. R. Bloem, Y. A. M. Grimbergen, M. Cramer, M. Willemsen, and A. H. Zwinderman, "Prospective assessment of falls in Parkinson's disease," Journal of Neurology, vol. 248, no. 11, pp. 950-958, 2001.

[10] M. Schenkman, T. M. Cutson, M. Kuchibhatla et al., "Exercise to improve spinal flexibility and function for people with Parkinson's disease: a randomized, controlled trial," Journal of the American Geriatrics Society, vol. 46, no. 10, pp. 1207-1216, 1998.

[11] T. Toole, M. A. Hirsch, A. Forkink, D. A. Lehman, and C. G. Maitland, "The effects of a balance and strength training program on equilibrium in Parkinsonism: a preliminary study," NeuroRehabilitation, vol. 14, no. 3, pp. 165-174, 2000.

[12] M. A. Hirsch, T. Toole, C. G. Maitland, and R. A. Rider, "The effects of balance training and high-intensity resistance training on persons with idiopathic Parkinson's disease," Archives of Physical Medicine and Rehabilitation, vol. 84, no. 8, pp. 11091117, 2003.

[13] A. Ashburn, L. Fazakarley, C. Ballinger, R. Pickering, L. D. McLellan, and C. Fitton, "A randomised controlled trial of a home based exercise programme to reduce the risk of falling among people with Parkinson's disease," Journal of Neurology, Neurosurgery and Psychiatry, vol. 78, no. 7, pp. 678-684, 2007.

[14] L. T. B. Gobbi, M. D. T. Oliveira-Ferreira, M. J. D. Caetano et al., "Exercise programs improve mobility and balance in people with Parkinson's disease," Parkinsonism \& Related Disorders, vol. 15, supplement 3, pp. S49-S52, 2009.

[15] I. S. Wong-Yu Is and M. Mak, "Effects of a context-specific physiotherapy exercise programme on enhancing balance performance and balance confidence in people with Parkinson's disease-a randomised controlled trial," Hong Kong Physiotherapy Journal, vol. 31, no. 2, pp. 100-101, 2013.

[16] J. Nocera, M. Horvat, and C. T. Ray, "Effects of home-based exercise on postural control and sensory organization in individuals with Parkinson disease," Parkinsonism \& Related Disorders, vol. 15, no. 10, pp. 742-745, 2009.

[17] B. Kara, A. Genc, B. D. Colakoglu, and R. Cakmur, "The effect of supervised exercises on static and dynamic balance in Parkinson's disease patients," NeuroRehabilitation, vol. 30, no. 4, pp. 351-357, 2012.

[18] G. Frazzitta, G. Abbruzzese, G. Bertotti, N. Boveri, G. Pezzoli, and R. Maestri, "Effectiveness of an intensive rehabilitation treatment on different Parkinson's disease subtypes," NeuroRehabilitation, vol. 33, no. 2, pp. 299-303, 2013.
[19] M. Capecci, C. Serpicelli, L. Fiorentini et al., "Postural rehabilitation and kinesio taping for axial postural disorders in Parkinson's disease," Archives of Physical Medicine and Rehabilitation, vol. 95, no. 6, pp. 1067-1075, 2014.

[20] D. Conradsson, N. Löfgren, A. Ståhle, and E. Franzén, "Is highly challenging and progressive balance training feasible in older adults with Parkinson's disease?" Archives of Physical Medicine and Rehabilitation, vol. 95, no. 5, pp. 1000-1003, 2014.

[21] L. E. Dibble, T. F. Hale, R. L. Marcus, J. P. Gerber, and P. C. LaStayo, "High intensity eccentric resistance training decreases bradykinesia and improves quality of life in persons with Parkinson's disease: a preliminary study," Parkinsonism \& Related Disorders, vol. 15, no. 10, pp. 752-757, 2009.

[22] D. M. Corcos, J. A. Robichaud, F. J. David et al., "A two-year randomized controlled trial of progressive resistance exercise for Parkinson's disease," Movement Disorders, vol. 28, no. 9, pp. 1230-1240, 2013.

[23] T. Herman, N. Giladi, L. Gruendlinger, and J. M. Hausdorff, "Six weeks of intensive treadmill training improves gait and quality of life in patients with Parkinson's disease: a pilot study," Archives of Physical Medicine and Rehabilitation, vol. 88, no. 9, pp. 11541158, 2007.

[24] M. Ganesan, T. N. Sathyaprabha, A. Gupta, and P. K. Pal, "Effect of partial weight-supported treadmill gait training on balance in patients with Parkinson disease," $P M \& R$, vol. 6, no. 1, pp. 22-33, 2014.

[25] O. Bello, J. A. Sanchez, V. Lopez-Alonso et al., "The effects of treadmill or overground walking training program on gait in Parkinson's disease," Gait \& Posture, vol. 38, no. 4, pp. 590-595, 2013.

[26] B. D. Cakit, M. Saracoglu, H. Genc, H. R. Erdem, and L. Inan, "The effects of incremental speed-dependent treadmill training on postural instability and fear of falling in Parkinson's disease," Clinical Rehabilitation, vol. 21, no. 8, pp. 698-705, 2007.

[27] T. Toole, C. G. Maitland, E. Warren, M. F. Hubmann, and L. Panton, "The effects of loading and unloading treadmill walking on balance, gait, fall risk, and daily function in Parkinsonism," NeuroRehabilitation, vol. 20, no. 4, pp. 307-322, 2005.

[28] N. T. Filippin, P. H. Lobo da Costa, and R. Mattioli, "Effects of treadmill-walking training with additional body load on quality of life in subjects with Parkinson's disease," Revista Brasileira de Fisioterapia, vol. 14, no. 4, pp. 344-350, 2010.

[29] A. Picelli, C. Melotti, F. Origano et al., "Robot-assisted gait training in patients with Parkinson disease: a randomized controlled trial," Neurorehabilitation and Neural Repair, vol. 26, no. 4, pp. 353-361, 2012.

[30] A. Picelli, C. Melotti, F. Origano, A. Waldner, R. Gimigliano, and N. Smania, "Does robotic gait training improve balance in Parkinson's disease? A randomized controlled trial," Parkinsonism \& Related Disorders, vol. 18, no. 8, pp. 990-993, 2012.

[31] N. Paker, D. Bugdayci, G. Goksenoglu, A. Sen, and N. Kesiktas, "Effects of robotic treadmill training on functional mobility, walking capacity, motor symptoms and quality of life in ambulatory patients with Parkinson's disease: a preliminary prospective longitudinal study," NeuroRehabilitation, vol. 33, no. 2, pp. 323328, 2013.

[32] M. E. Hackney and G. M. Earhart, "Tai Chi improves balance and mobility in people with Parkinson disease," Gait \& Posture, vol. 28, no. 3, pp. 456-460, 2008.

[33] W. W. N. Tsang, "Tai Chi training is effective in reducing balance impairments and falls in patients with Parkinson's disease," Journal of Physiotherapy, vol. 59, no. 1, article 55, 2013. 
[34] F. Li and K. Fitzgerald, "Postural stability in Parkinson's disease patients after Tai Chi training: a randomized controlled trial," Parkinsonism \& Related Disorders, vol. 18, supplement 2, p. S155, 2012.

[35] H. D. Kim, H. D. Jae, and J. H. Jeong, "Tai Chi exercise can improve the obstacle negotiating ability of people with Parkinson's Disease: a preliminary study," Journal of Physical Therapy Science, vol. 26, no. 7, pp. 1025-1030, 2014.

[36] Q. Gao, A. Leung, Y. Yang et al., "Effects of Tai Chi on balance and fall prevention in Parkinson's disease: a randomized controlled trial," Clinical Rehabilitation, vol. 28, no. 8, pp. 748-753, 2014.

[37] S. Amano, J. R. Nocera, S. Vallabhajosula et al., "The effect of Tai Chi exercise on gait initiation and gait performance in persons with Parkinson's disease," Parkinsonism \& Related Disorders, vol. 19, no. 11, pp. 955-960, 2013.

[38] S. L. Loftus, "Qi Gong to improve postural stability (QTIPS) for Parkinson fall prevention: a neuroplasticity approach," Topics in Geriatric Rehabilitation, vol. 30, no. 1, pp. 58-69, 2014.

[39] N. Sharma, K. Robbins, K. Wagner, and Y. Colgrove, "A randomized controlled pilot study of the therapeutic effects of yoga in people with Parkinson's disease," International Journal of Yoga, vol. 8, no. 1, pp. 74-79, 2015.

[40] L. K. Boulgarides, E. Barakatt, and B. Coleman-Salgado, "Measuring the effect of an eight-week adaptive yoga program on the physical and psychological status of individuals with Parkinson's disease. A pilot study," International Journal of Yoga Therapy, vol. 24, pp. 31-41, 2014.

[41] J.-F. Esculier, J. Vaudrin, P. Bériault, K. Gagnon, and L. E. Tremblay, "Home-based balance training programme using Wii Fit with balance board for Parkinsons's disease: a pilot study," Journal of Rehabilitation Medicine, vol. 44, no. 2, pp. 144-150, 2012.

[42] P. V. Mhatre, I. Vilares, S. M. Stibb et al., "Wii Fit balance board playing improves balance and gait in Parkinson disease," Physical Medicine \& Rehabilitation, vol. 5, no. 9, pp. 769-777, 2013.

[43] N. B. Herz, S. H. Mehta, K. D. Sethi, P. Jackson, P. Hall, and J. C. Morgan, "Nintendo Wii rehabilitation ('Wii-hab') provides benefits in Parkinson's disease," Parkinsonism and Related Disorders, vol. 19, no. 11, pp. 1039-1042, 2013.

[44] J. E. Pompeu, F. A. D. S. Mendes, K. G. D. Silva et al., "Effect of Nintendo Wii-based motor and cognitive training on activities of daily living in patients with Parkinson's disease: a randomised clinical trial," Physiotherapy, vol. 98, no. 3, pp. 196-204, 2012.

[45] J. E. Pompeu, L. A. Arduini, A. R. Botelho et al., "Feasibility, safety and outcomes of playing Kinect Adventures! for people with Parkinson's disease: a pilot study," Physiotherapy, vol. 100, no. 2, pp. 162-168, 2014.

[46] S. Summa, A. Basteris, E. Betti, and V. Sanguineti, "A feasibility study on using kinect for the rehabilitation in persons with Parkinson's disease," Gait \& Posture, vol. 37, supplement 1, p. S15, 2013.

[47] M. Shih, Y. Yang, and R. Wang, "Effects of virtual-reality based balance training on posture control in Parkinson's disease," Proceedings of the Physiological Society, vol. 31, pp. 283-284, 2014.

[48] M. R. van den Heuvel, G. Kwakkel, P. J. Beek, H. W. Berendse, A. Daffertshofer, and E. E. van Wegen, "Effects of augmented visual feedback during balance training in Parkinson's disease: a pilot randomized clinical trial," Parkinsonism \& Related Disorders, vol. 20, pp. 1352-1358, 2014.
[49] N. Y. Lee, D. K. Lee, and H. S. Song, "Effect of virtual reality dance exercise on the balance, activities of daily living, and depressive disorder status of Parkinson's disease patients," Journal of Physical Therapy Science, vol. 27, no. 1, pp. 145-147, 2015.

[50] A. Azarpaikan, H. T. Torbati, and M. Sohrabi, "Neurofeedback and physical balance in Parkinson's patients," Gait \& Posture, vol. 40, no. 1, pp. 177-181, 2014.

[51] A. Mirelman, T. Herman, S. Nicolai et al., "Audio-biofeedback training for posture and balance in patients with Parkinson's disease," Journal of NeuroEngineering \& Rehabilitation, vol. 8, article 35, 2011.

[52] F. Asseman, A. M. Bronstein, and M. A. Gresty, "Using vibrotactile feedback of instability to trigger a forward compensatory stepping response," Journal of Neurology, vol. 254, no. 11, pp. 1555-1561, 2007.

[53] D. Marchant, J. L. Sylvester, and G. M. Earhart, "Effects of a short duration, high dose contact improvisation dance workshop on Parkinson disease: a pilot study," Complementary Therapies in Medicine, vol. 18, no. 5, pp. 184-190, 2010.

[54] G. Batson, "Feasibility of an intensive trial of modern dance for adults with Parkinson disease," Complementary Health Practice Review, vol. 15, no. 2, pp. 65-83, 2010.

[55] M. E. Hackney and G. M. Earhart, "Effects of dance on movement control in Parkinson's disease: a comparison of Argentine tango and American ballroom," Journal of Rehabilitation Medicine, vol. 41, no. 6, pp. 475-481, 2009.

[56] L. Heiberger, C. Maurer, F. Amtage et al., "Impact of a weekly dance class on the functional mobility and on the quality of life of individuals with Parkinson's disease," Frontiers in Aging Neuroscience, vol. 3, article 14, 2011.

[57] E. Rosario, E. Aiello, K. S. Paulus et al., "Effects of dance therapy on balance, gait and neuro-psychological performances in patients with Parkinson's disease and postural instability," Disability and Rehabilitation, vol. 2, no. 3, p. 45, 2012.

[58] H. Hashimoto, S. Takabatake, H. Miyaguchi, H. Nakanishi, and Y. Naitou, "Effects of dance on motor functions, cognitive functions, and mental symptoms of Parkinson's disease: a quasirandomized pilot trial," Complementary Therapies in Medicine, vol. 23, no. 2, pp. 210-219, 2015.

[59] O. Westheimer, C. McRae, C. Henchcliffe et al., "Dance for PD: a preliminary investigation of effects on motor function and quality of life among persons with Parkinson's disease (PD)," Journal of Neural Transmission, 2015.

[60] S. Houston and A. McGill, "A mixed-methods study into ballet for people living with Parkinson's," Arts \& Health, vol. 5, no. 2, pp. 103-119, 2013.

[61] M. E. Hackney and G. M. Earhart, "Short duration, intensive tango dancing for Parkinson disease: an uncontrolled pilot study," Complementary Therapies in Medicine, vol. 17, no. 4, pp. 203-207, 2009.

[62] M. E. Hackney and G. M. Earhart, "Health-related quality of life and alternative forms of exercise in Parkinson disease," Parkinsonism \& Related Disorders, vol. 15, no. 9, pp. 644-648, 2009.

[63] M. E. Hackney, S. Kantorovich, and G. M. Earhart, "A study on the effects of argentine tango as a form of partnered dance for those with Parkinson disease and the healthy elderly," American Journal of Dance Therapy, vol. 29, no. 2, pp. 109-127, 2007. 
[64] S. R. Romenets, J. Anang, S. M. Fereshtehnejad, A. Pelletier, and R. Postuma, "Tango for treatment of motor and non-motor manifestations in Parkinson's disease: a randomized control study," Complementary Therapies in Medicine, vol. 23, no. 2, pp. 175-184, 2015.

[65] M. H. Nilsson, P.-A. Fransson, G.-B. Jarnlo, M. Magnusson, and S. Rehncrona, "The effects of high frequency subthalamic stimulation on balance performance and fear of falling in patients with Parkinson's disease," Journal of NeuroEngineering \& Rehabilitation, vol. 6, article 13, 2009.

[66] J. Vivas, P. Arias, and J. Cudeiro, "Aquatic therapy versus conventional land-based therapy for Parkinson's disease: an open-label pilot study," Archives of Physical Medicine and Rehabilitation, vol. 92, no. 8, pp. 1202-1210, 2011.

[67] G. Ebersbach, D. Edler, O. Kaufhold, and J. Wissel, "Whole body vibration versus conventional physiotherapy to improve balance and gait in Parkinson's disease," Archives of Physical Medicine and Rehabilitation, vol. 89, no. 3, pp. 399-403, 2008.

[68] P. Lauhoff, N. Murphy, C. Doherty, and N. F. Horgan, "A controlled clinical trial investigating the effects of cycle ergometry training on exercise tolerance, balance and quality of life in patients with Parkinson's disease," Disability \& Rehabilitation, vol. 35, no. 5, pp. 382-387, 2013.

[69] D. Kaski, R. O. Dominguez, J. H. Allum, A. F. Islam, and A. M. Bronstein, "Combining physical training with transcranial direct current stimulation to improve gait in Parkinson's disease: a pilot randomized controlled study," Clinical Rehabilitation, vol. 28, no. 11, pp. 1115-1124, 2014.

[70] X. Shen and M. K. Y. Mak, "Repetitive step training with preparatory signals improves stability limits in patients with Parkinson's disease," Journal of Rehabilitation Medicine, vol. 44, no. 11, pp. 944-949, 2012.

[71] M. E. Morris, R. Iansek, and B. Kirkwood, "A randomized controlled trial of movement strategies compared with exercise for people with Parkinson's disease," Movement Disorders, vol. 24, no. 1, pp. 64-71, 2009.

[72] P. L. Scalzo, C. R. Flores, J. R. Marques, S. C. D. O. Robini, and A. L. Teixeira, "Impact of changes in balance and walking capacity on the quality of life in patients with Parkinson's disease," Arquivos de Neuro-Psiquiatria, vol. 70, no. 2, pp. 119-124, 2012.

[73] C. D. Ward, "What contributes to quality of life in patients with Parkinson's disease?" Journal of Neurology, Neurosurgery and Psychiatry, vol. 69, no. 3, pp. 289-290, 2000.

[74] D. Muslimović, B. Post, J. D. Speelman, B. Schmand, R. J. de Haan, and CARPA Study Group, "Determinants of disability and quality of life in mild to moderate Parkinson disease," Neurology, vol. 70, no. 23, pp. 2241-2247, 2008.

[75] S. Rahman, H. J. Griffin, N. P. Quinn, and M. Jahanshahi, "Quality of life in Parkinson's disease: the relative importance of the symptoms," Movement Disorders, vol. 23, no. 10, pp. 14281434, 2008.

[76] L. J. Melton III, C. L. Leibson, S. J. Achenbach et al., "Fracture risk after the diagnosis of Parkinson's disease: influence of concomitant dementia," Movement Disorders, vol. 21, no. 9, pp. 1361-1367, 2006.

[77] E. L. Stegemöller, J. Nocera, I. Malaty, M. Shelley, M. S. Okun, and C. J. Hass, "Timed up and go, cognitive, and quality-of-life correlates in Parkinson's disease," Archives of Physical Medicine and Rehabilitation, vol. 95, no. 4, pp. 649-655, 2014.
[78] A. N. Nisenzon, M. E. Robinson, D. Bowers, E. Banou, I. Malaty, and M. S. Okun, "Measurement of patient-centered outcomes in Parkinson's disease: what do patients really want from their treatment?" Parkinsonism and Related Disorders, vol. 17, no. 2, pp. 89-94, 2011.

[79] S.-E. Soh, M. E. Morris, and J. L. McGinley, "Determinants of health-related quality of life in Parkinson's disease: a systematic review," Parkinsonism \& Related Disorders, vol. 17, no. 1, pp. 1-9, 2011.

[80] N. Caballol, M. J. Martí, and E. Tolosa, "Cognitive dysfunction and dementia in Parkinson disease," Movement Disorders, vol. 22, no. 17, pp. S358-S366, 2007.

[81] K. Ossowska and E. Lorenc-Koci, "Depression in Parkinson's disease," Pharmacological Reports, vol. 65, no. 6, pp. 1545-1557, 2013.

[82] M. Visser, S. M. Van Rooden, D. Verbaan, J. Marinus, A. M. Stiggelbout, and J. J. Van Hilten, "A comprehensive model of health-related quality of life in Parkinson's disease," Journal of Neurology, vol. 255, no. 10, pp. 1580-1587, 2008.

[83] L. C. Routh, J. L. Black, and J. E. Ahlskog, "Parkinson's disease complicated by anxiety," Mayo Clinic Proceedings, vol. 62, no. 8, pp. 733-735, 1987.

[84] A. F. G. Leentjens, K. Dujardin, L. Marsh, P. Martinez-Martin, I. H. Richard, and S. E. Starkstein, "Symptomatology and markers of anxiety disorders in Parkinson's disease: a crosssectional study," Movement Disorders, vol. 26, no. 3, pp. 484492, 2011.

[85] G. M. Pontone, J. R. Williams, K. E. Anderson et al., "Prevalence of anxiety disorders and anxiety subtypes in patients with Parkinson's disease," Movement Disorders, vol. 24, no. 9, pp. 1333-1338, 2009.

[86] N. N. W. Dissanayaka, A. Sellbach, S. Matheson et al., "Anxiety disorders in Parkinson's disease: prevalence and risk factors," Movement Disorders, vol. 25, no. 7, pp. 838-845, 2010.

[87] C. Pont-Sunyer, A. Hotter, C. Gaig et al., "The Onset of Nonmotor Symptoms in Parkinson's disease (The ONSET PDStudy)," Movement Disorders, vol. 30, no. 2, pp. 229-237, 2015.

[88] D. Aarsland, K. Brønnick, G. Alves et al., "The spectrum of neuropsychiatric symptoms in patients with early untreated Parkinson's disease," Journal of Neurology, Neurosurgery and Psychiatry, vol. 80, no. 8, pp. 928-930, 2009.

[89] P. Barone, A. Antonini, C. Colosimo et al., "The PRIAMO study: a multicenter assessment of nonmotor symptoms and their impact on quality of life in Parkinson's disease," Movement Disorders, vol. 24, no. 11, pp. 1641-1649, 2009.

[90] K. Dujardin, P. Sockeel, M. Delliaux, A. Destée, and L. Defebvre, "Apathy may herald cognitive decline and dementia in Parkinson's disease," Movement Disorders, vol. 24, no. 16, pp. 2391-2397, 2009.

[91] K. F. Pedersen, J. P. Larsen, G. Alves, and D. Aarsland, "Prevalence and clinical correlates of apathy in Parkinson's disease: a community-based study," Parkinsonism and Related Disorders, vol. 15, no. 4, pp. 295-299, 2009.

[92] J. H. Friedman, "Parkinson's disease psychosis 2010: a review article," Parkinsonism \& Related Disorders, vol. 16, no. 9, pp. 553560, 2010.

[93] A. Hassan, S. Vallabhajosula, L. B. Zahodne et al., "Correlations of apathy and depression with postural instability in Parkinson disease," Journal of the Neurological Sciences, vol. 338, no. 1-2, pp. 162-165, 2014. 
[94] E. P. Pasman, C. D. Murnaghan, B. R. Bloem, and M. G. Carpenter, "Balance problems with Parkinson's disease: are they anxiety-dependent?" Neuroscience, vol. 177, pp. 283-291, 2011.

[95] C. D. Balaban and J. F. Thayer, "Neurological bases for balanceanxiety links," Journal of Anxiety Disorders, vol. 15, no. 1-2, pp. 53-79, 2001.

[96] C. D. Balaban, "Vestibular nucleus projections to the parabrachial nucleus in rabbits: implications for vestibular influences on the autonomic nervous system," Experimental Brain Research, vol. 108, no. 3, pp. 367-381, 1996.

[97] D. S. Charney, D. S. Charney, A. Deutch, and A. Deutch, "A functional neuroanatomy of anxiety and fear: implications for the pathophysiology and treatment of anxiety disorders," Critical Reviews in Neurobiology, vol. 10, no. 3-4, pp. 419-446, 1996.

[98] J. A. Ricardo and E. T. Koh, "Anatomical evidence of direct projections from the nucleus of the solitary tract to the hypothalamus, amygdala, and other forebrain structures in the rat," Brain Research, vol. 153, no. 1, pp. 1-26, 1978.

[99] D. Riche, J. de Pommery, and D. Menetrey, "Neuropeptides and catecholamines in efferent projections of the nuclei of the solitary tract in the rat," Journal of Comparative Neurology, vol. 293, no. 3, pp. 399-424, 1990.

[100] M. M. Moga, R. P. Weis, and R. Y. Moore, "Efferent projections of the paraventricular thalamic nucleus in the rat," Journal of Comparative Neurology, vol. 359, no. 2, pp. 221-238, 1995.

[101] J. D. Porter and C. D. Balaban, "Connections between the vestibular nuclei and brain stem regions that mediate autonomic function in the rat," Journal of Vestibular Research: Equilibrium and Orientation, vol. 7, no. 1, pp. 63-76, 1997.

[102] A. R. Damasio, "Emotion in the perspective of an integrated nervous system," Brain Research Reviews, vol. 26, no. 2-3, pp. 83-86, 1998.

[103] A. W. Goddard and D. S. Charney, "Toward an integrated neurobiology of panic disorder," Journal of Clinical Psychiatry, vol. 58, no. 2, pp. 4-11, 1997.

[104] S. Shefer, C. Gordon, K. B. Avraham, and M. Mintz, "Balance deficit enhances anxiety and balance training decreases anxiety in vestibular mutant mice," Behavioural Brain Research, vol. 276, pp. 76-83, 2015.

[105] G. P. Reppa, “The effects of a new program (balance \& reform) on trait anxiety and self-esteem: a pilot study," Procedia-Social and Behavioral Sciences, vol. 84, pp. 230-232, 2013.

[106] O. Bart, Y. Bar-Haim, E. Weizman, M. Levin, A. Sadeh, and M. Mintz, "Balance treatment ameliorates anxiety and increases self-esteem in children with comorbid anxiety and balance disorder," Research in Developmental Disabilities, vol. 30, no. 3 , pp. 486-495, 2009.

[107] O. Erez, C. R. Gordon, J. Sever, A. Sadeh, and M. Mintz, "Balance dysfunction in childhood anxiety: findings and theoretical approach," Journal of Anxiety Disorders, vol. 18, no. 3, pp. 341356, 2004.

[108] A. Sagna, J. J. Gallo, and G. M. Pontone, "Systematic review of factors associated with depression and anxiety disorders among older adults with Parkinson's disease," Parkinsonism and Related Disorders, vol. 20, pp. 708-715, 2014.

[109] E. R. Siemers, A. Shekhar, K. Quaid, and H. Dickson, "Anxiety and motor performance in Parkinson's disease," Movement Disorders, vol. 8, no. 4, pp. 501-506, 1993.

[110] K. A. E. Martens, C. G. Ellard, Q. J. Almeida, and R. Balasubramaniam, "Does anxiety cause freezing of gait in Parkinson's disease?” PLoS ONE, vol. 9, no. 9, Article ID e106561, 2014.
[111] J. S. A. M. Reijnders, B. Scholtissen, W. E. J. Weber, P. Aalten, F. R. J. Verhey, and A. F. G. Leentjens, "Neuroanatomical correlates of apathy in Parkinson's disease: a magnetic resonance imaging study using voxel-based morphometry," Movement Disorders, vol. 25, no. 14, pp. 2318-2325, 2010.

[112] M. Benoit and P. H. Robert, "Imaging correlates of apathy and depression in Parkinson's disease," Journal of the Neurological Sciences, vol. 310, no. 1-2, pp. 58-60, 2011.

[113] P. G. Frisina, V. Haroutunian, and L. S. Libow, "The neuropathological basis for depression in Parkinson's disease," Parkinsonism and Related Disorders, vol. 15, no. 2, pp. 144-148, 2009.

[114] D. A. Gallagher and A. Schrag, "Psychosis, apathy, depression and anxiety in Parkinson's disease," Neurobiology of Disease, vol. 46, no. 3, pp. 581-589, 2012.

[115] J. S. A. M. Reijnders, U. Ehrt, R. Lousberg, D. Aarsland, and A. F. G. Leentjens, "The association between motor subtypes and psychopathology in Parkinson's disease," Parkinsonism and Related Disorders, vol. 15, no. 5, pp. 379-382, 2009.

[116] S. Lord, B. Galna, S. Coleman, D. Burn, and L. Rochester, "Mild depressive symptoms are associated with gait impairment in early Parkinson's disease," Movement Disorders, vol. 28, no. 5, pp. 634-639, 2013.

[117] D. J. Burn, "The effects of deep brain stimulation and levodopa on postural sway in subjects with Parkinson's disease," Journal of Neurology, Neurosurgery and Psychiatry, vol. 73, no. 3, article 240, 2002.

[118] A. Bauman and M. E. M. M. M. Schoo, "Health benefits of physical activity for older adults-epidemiological approaches to the evidence," in Optimizing Exercise and Physical Activity in Older People, pp. 1-25, Butterworth-Heinemann, Oxford, UK, 2004.

[119] A. D. Smith and M. J. Zigmond, "Can the brain be protected through exercise? Lessons from an animal model of parkinsonism," Experimental Neurology, vol. 184, no. 1, pp. 31-39, 2003.

[120] O. Bello, G. Marquez, M. Camblor, and M. Fernandez-DelOlmo, "Mechanisms involved in treadmill walking improvements in Parkinson's disease," Gait and Posture, vol. 32, no. 1, pp. 118-123, 2010.

[121] A. Ross and S. Thomas, "The health benefits of yoga and exercise: a review of comparison studies," Journal of Alternative and Complementary Medicine, vol. 16, no. 1, pp. 3-12, 2010.

[122] J. A. Raub, "Psychophysiologic effects of Hatha Yoga on musculoskeletal and cardiopulmonary function: a literature review," Journal of Alternative and Complementary Medicine, vol. 8, no. 6, pp. 797-812, 2002.

[123] A. A. Schmid, M. van Puymbroeck, and D. M. Koceja, "Effect of a 12-week yoga intervention on fear of falling and balance in older adults: a pilot study," Archives of Physical Medicine and Rehabilitation, vol. 91, no. 4, pp. 576-583, 2010.

[124] G. Moriello, C. Denio, M. Abraham, D. DeFrancesco, and J. Townsley, "Incorporating yoga into an intense physical therapy program in someone with Parkinson's disease: a case report," Journal of Bodywork and Movement Therapies, vol. 17, no. 4, pp. 408-417, 2013.

[125] E. Hall, G. Verheyden, and A. Ashburn, "Effect of a yoga programme on an individual with Parkinson's disease: a singlesubject design," Disability and Rehabilitation, vol. 33, no. 15-16, pp. 1483-1489, 2011.

[126] E. Bisson, B. Contant, H. Sveistrup, and Y. Lajoie, "Functional balance and dual-task reaction times in older adults are improved by virtual reality and biofeedback training," Cyberpsychology \& Behavior, vol. 10, no. 1, pp. 16-23, 2007. 
[127] D. P. Butler and K. Willett, "Wii-habilitation: is there a role in trauma?” Injury, vol. 41, no. 9, pp. 883-885, 2010.

[128] C.-Y. Yen, K.-H. Lin, M.-H. Hu, R.-M. Wu, T.-W. Lu, and C.-H. Lin, "Effects of virtual reality-augmented balance training on sensory organization and attentional demand for postural control in people with Parkinson disease: a randomized controlled trial," Physical Therapy, vol. 91, no. 6, pp. 862-874, 2011.

[129] M. Faridnia, M. Shojaei, and A. Rahimi, "The effect of neurofeedback training on the anxiety of elite female swimmers," Annals of Biological Research, vol. 3, no. 2, pp. 1020-1028, 2012.

[130] X. J. Caro and E. F. Winter, "EEG biofeedback treatment improves certain attention and somatic symptoms in fibromyalgia: a pilot study," Applied Psychophysiology Biofeedback, vol. 36, no. 3, pp. 193-200, 2011.

[131] K. Robinson, A. Dennison, D. Roalf et al., "Falling risk factors in Parkinson's disease," NeuroRehabilitation, vol. 20, no. 3, pp. 169-182, 2005.

[132] A. Contreras and F. Grandas, "Risk of falls in Parkinson's disease: a cross-sectional study of 160 patients," Parkinson's Disease, vol. 2012, Article ID 362572, 10 pages, 2012.

[133] M. Rossi-Izquierdo, A. Ernst, A. Soto-Varela et al., "Vibrotactile neurofeedback balance training in patients with Parkinson's disease: reducing the number of falls," Gait \& Posture, vol. 37, no. 2, pp. 195-200, 2013.

[134] J.-C. Kattenstroth, I. Kolankowska, T. Kalisch, and H. R. Dinse, "Superior sensory, motor, and cognitive performance in elderly individuals with multi-year dancing activities," Frontiers in Aging Neuroscience, vol. 2, article 31, 2010.

[135] M. E. Hackney and G. M. Earhart, "Effects of dance on gait and balance in Parkinsons disease: a comparison of partnered and nonpartnered dance movement," Neurorehabilitation and Neural Repair, vol. 24, no. 4, pp. 384-392, 2010.

[136] M. Baláž, "Deep brain stimulation in Parkinson's disease," Neurologie Pro Praxi, vol. 14, pp. 229-231, 2013.

[137] M. H. Nilsson, A. L. Törnqvist, and S. Rehncrona, "Deep-brain stimulation in the subthalamic nuclei improves balance performance in patients with Parkinson's disease, when tested without anti-parkinsonian medication," Acta Neurologica Scandinavica, vol. 111, no. 5, pp. 301-308, 2005.

[138] M. I. Hariz, S. Rehncrona, N. P. Quinn, J. D. Speelman, and C. Wensing, "Multicenter study on deep brain stimulation in Parkinson's disease: an independent assessment of reported adverse events at 4 years," Movement Disorders, vol. 23, no. 3, pp. 416-421, 2008.

[139] G. Tommasi, L. Lopiano, M. Zibetti et al., "Freezing and hypokinesia of gait induced by stimulation of the subthalamic region," Journal of the Neurological Sciences, vol. 258, no. 1-2, pp. 99-103, 2007.

[140] M. Bakker, R. A. J. Esselink, M. Munneke, P. Limousin-Dowsey, H. D. Speelman, and B. R. Bloem, "Effects of stereotactic neurosurgery on postural instability and gait in Parkinson's disease," Movement Disorders, vol. 19, no. 9, pp. 1092-1099, 2004.

[141] P. Krack, A. Batir, N. van Blercom et al., "Five-year follow-up of bilateral stimulation of the subthalamic nucleus in advanced Parkinson's disease," The New England Journal of Medicine, vol. 349, no. 20, pp. 1925-1934, 2003.

[142] A. Fasano, L. M. Romito, A. Daniele et al., "Motor and cognitive outcome in patients with Parkinson's disease 8 years after subthalamic implants," Brain, vol. 133, no. 9, pp. 2664-2676, 2010.
[143] W. M. M. Schüpbach, N. Chastan, M. L. Welter et al., "Stimulation of the subthalamic nucleus in Parkinson's disease: a 5 year follow up," Journal of Neurology, Neurosurgery and Psychiatry, vol. 76, no. 12, pp. 1640-1644, 2005.

[144] L. M. Romito, M. F. Contarino, N. Vanacore, A. R. Bentivoglio, M. Scerrati, and A. Albanese, "Replacement of dopaminergic medication with subthalamic nucleus stimulation in Parkinson's disease: long-term observation," Movement Disorders, vol. 24, no. 4, pp. 557-563, 2009.

[145] P. Plaha and S. S. Gill, "Bilateral deep brain stimulation of the pedunculopontine nucleus for Parkinson's disease," NeuroReport, vol. 16, no. 17, pp. 1883-1887, 2005.

[146] A. Stefani, A. M. Lozano, A. Peppe et al., "Bilateral deep brain stimulation of the pedunculopontine and subthalamic nuclei in severe Parkinson's disease," Brain, vol. 130, no. 6, pp. 1596-1607, 2007.

[147] I. Mathieson, S. Curran, S. Hallam, and J. Corne.

[148] S. A. Combs, D. Diehl, W. H. Staples et al., "Boxing training for patients with parkinson disease: a case series," Physical Therapy, vol. 91, no. 1, pp. 132-142, 2011.

[149] P. Kluding and P. Q. McGinnis, "Multidimensional exercise for people with Parkinson's disease: a case report," Physiotherapy Theory and Practice, vol. 22, no. 3, pp. 153-162, 2006.

[150] T. Ellis, J. K. Boudreau, T. R. DeAngelis et al., "Barriers to exercise in people with parkinson disease," Physical Therapy, vol. 93, no. 5, pp. 628-636, 2013. 


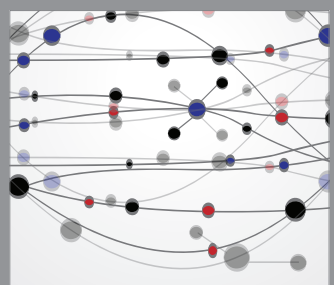

The Scientific World Journal
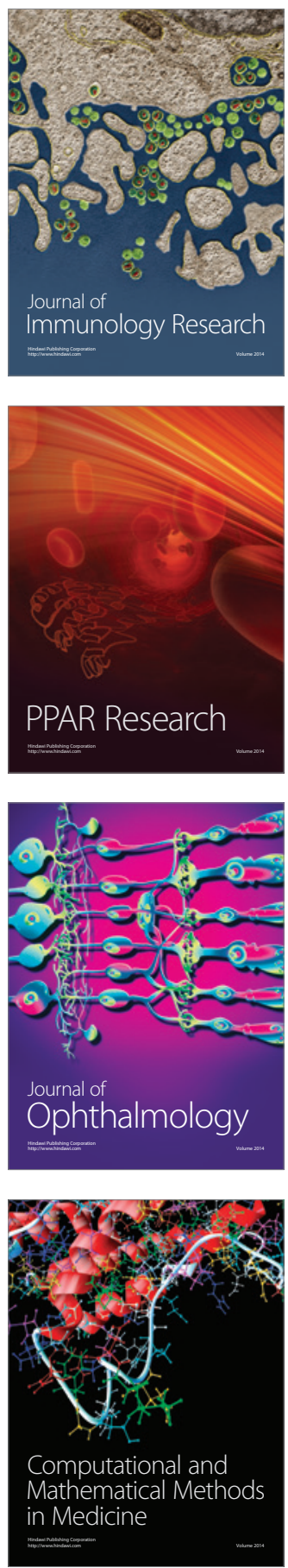

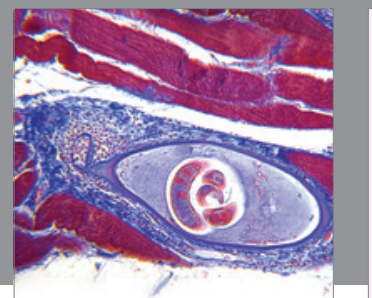

Gastroenterology

Research and Practice
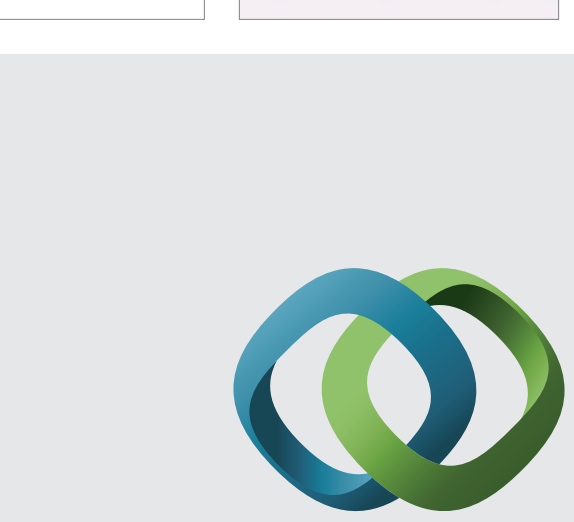

\section{Hindawi}

Submit your manuscripts at

http://www.hindawi.com
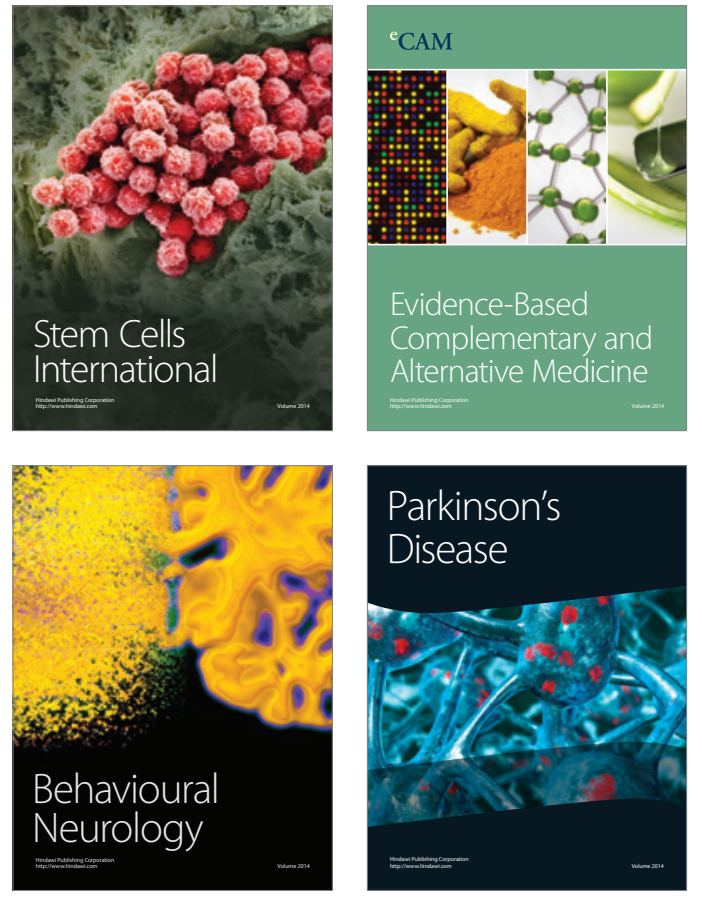
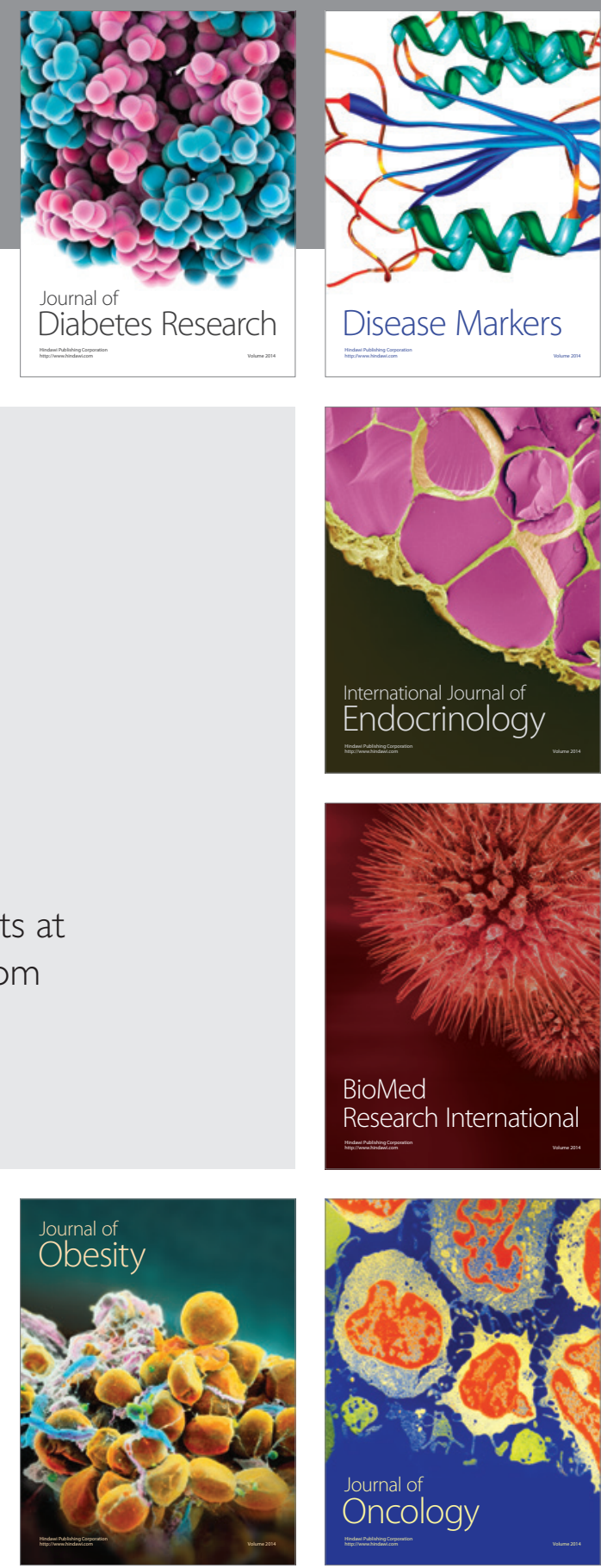

Disease Markers
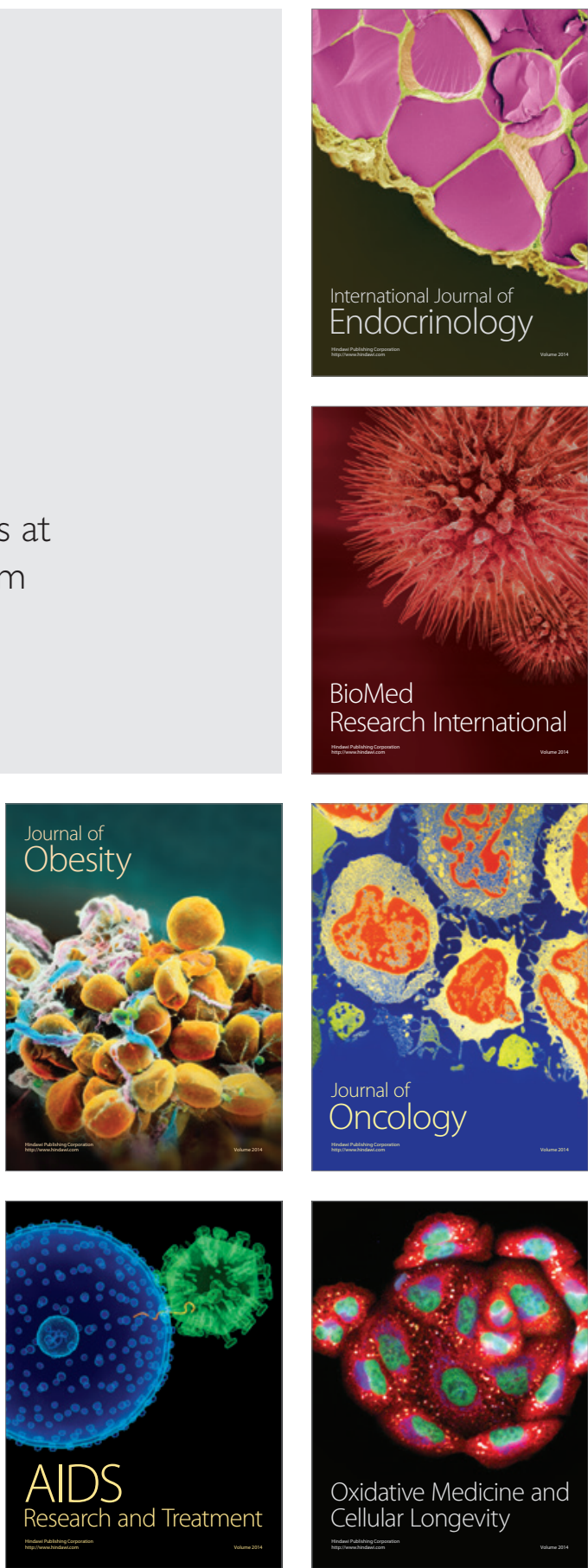